\title{
Malignant Paraganglioma; a Story of a Long Time Survival
}

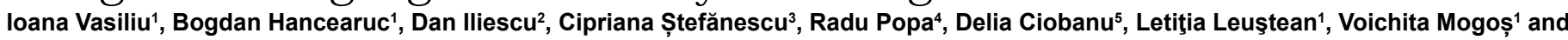
Carmen Vulpoi ${ }^{1 *}$

${ }^{1}$ Department of Endocrinology, University of Medicine and Pharmacy “Grigore T. Popa” lași, Romania

${ }^{2}$ Department of Cardiology, University of Medicine and Pharmacy "Grigore T. Popa” lași, Romania

${ }^{3}$ Department of Nuclear Medicine, University of Medicine and Pharmacy "Grigore T. Popa" lasi, Romania

${ }^{4}$ Department of Vascular Surgery, University of Medicine and Pharmacy "Grigore T. Popa" lași, Romania

${ }^{5}$ Department of Pathology, University of Medicine and Pharmacy “Grigore T. Popa" lași, Romania

\begin{abstract}
Pheochromocytoma and paraganglioma are catecholamine secreting tumors. Malignancy is uncommon - approximately $10 \%$ for pheochromocytoma and $20 \%$ for paraganglyoma. Surgery, when possible, is the first line treatment. Prognosis is poor because of a frequent local recurrence and/or metastases and the lack of specific chemotherapeutic agents. We report the case of a 60 years old man who was hospitalized at the age of 48 for episodes of paroxystic hypertension with spells. The high levels of vanillylmandelic acid (VMA), more than $50 \mathrm{mg} / 24 \mathrm{~h}$ at 3 determinations, confirmed the excess of catecholamine, but the CT scan failed to reveal the tumor. The iodine-131meta-iodobenzylguanidine (I-MIBG) scintigraphy showed the presence of a $1.5 \mathrm{~cm}$ nodule in the left abdominal paraaortic region. The patient refused surgery and had a satisfactory evolution with antihypertensive therapy. 11 years later he was admitted in the Vascular Surgery Department for acute ischemia of inferior limbs; a voluminous para-aortic tumor was diagnosed and resected. The pathology confirmed paraganglioma and described some atypical cells without being able to discriminate between benign or malignant pattern. Anamnesis could not identify any other case in the family. After another year he was admitted in the Endocrine Department for the reappearance of the adrenergic syndrome, with VMA at $30.8 \mathrm{mg} / 24 \mathrm{~h}$. The thoracic and abdominal CT-scan showed abdominal and thoracic metastatic tumors. The patient was referred to a specialized center were octeotride scintigraphy confirmed local recurrence and metastatic tumors in the lungs. He was treated with Sunitinib with a good initial response and he died after 16 years from the initial diagnostic of paraganglioma.
\end{abstract}

Keywords: Paraganlioma; pheochromocytoma; Surgery; Adrenergic syndrome; Long term outcome

\section{Introduction}

Pheochromocytoma and paraganglioma are catecholamine secreting tumors. The term of pheocromocytome is reserved to intraadrenal tumors, the tumors derived from extraadrenal cromaphine cells being defined as paragnagliomas. [1,2]. The distinction between pheochromocytoma and paraganglioma is important because of its implications: evolution, risk for malignancy, and genetic testing [1]. Catecholamine-secreting tumors are rare, with an annual incidence of 2 to 8 cases per 1 million people [3]. Based on screening studies for secondary causes of hypertension in outpatients, the prevalence of pheochromocytoma has been estimated at $0.1 \%$ to $0.6 \%$ [4-7].

Paragangliomas, representing $10 \%$ of the catecholamine secreting tumors, are also characterized by their site: along the paraaortic sympathetic chain, within the organ of Zuckerkandl (at the origin of the inferior mesenteric artery), in the wall of the urinary bladder, and along the sympathetic chain in the neck or mediastinum. During early postnatal life, the extra-adrenal sympathetic paraganglionary tissues are prominent; later they degenerate, leaving residual foci associated with the vagus nerves, carotid vessels, aortic arch, pulmonary vessels, and mesenteric arteries. Odd locations for paragangliomas include the neck, intra-atrial cardiac septum, spermatic cord, vagina, scrotum, and sacrococcygeal region $[1,8]$. Paragangliomas in the head and neck region (e.g. carotid body tumors, glomus tumors, chemodectoma) usually arise from parasympathetic tissue and typically do not hypersecrete catecholamines (CA) and metanephrines (MN) $[8,9]$. On the other hand paragangliomas of the mediastinum, abdomen, and pelvis usually arise from sympathetic chromaffin tissue and do hypersecrete CA and MN [8,9].

Recent genetic advances helped to recognize the genetic origin of
$1 / 3$ of malignant pheochromocytoma and paragnagliioma. Hereditary catecholamine-secreting tumors typically manifest at a younger age than sporadic neoplasms do. Sporadic pheochromocytoma typically is diagnosed on the basis of symptoms or as an incidental discovery on CT or MRI, whereas syndromic pheochromocytoma (associated with familial syndromes like multiple endocrine neoplasia, von Hippel Lindau syndrome or neurofibromatosis type 1) is frequently diagnosed earlier in the course of disease as a result of biochemical surveillance or genetic testing $[1,10]$.

Approximately $15 \%$ to $25 \%$ of patients with catecholamine secreting tumors have germline mutations (inherited mutations present in all cells of the body). Paragangliomas are characterized by loss of function mutation in the subunits A, B, C, and D subunits of succinate dehydrogenase suunit $B$ gene, and a mitochondrial enzymatic complex. The affected subunit seams to determine the clinical features of the disease and the risk of malignancy $[10,11]$.

\section{Case Report}

We report the case of a 60 years old man who was hospitalized

*Corresponding author: Carmen Vulpoi, MD, PhD, Professor of Endocrinology, Department of Endocrinology, University of Medicine and Pharmacy "Gr.T. Popa", Str. Universității, No 1, 700115, Iași, Romania, Tel: +40 (0) 723204603 Fax: +40 (0) 7232046 03; E-mail: c.vulpoi@yahoo.fr

Received February 01, 2014; Accepted March 02, 2014; Published Septembe 20,2014

Citation: Vasiliu I, Hancearuc B, lliescu D, tefănescu C, Popa R, et al. Theoretica and Practical Considerations in Colo-Rectal Diverticulosis Complicated with Multiple Sigmoido-Recto-Vesical Fistulas. Journal of Surgery [Jurnalul de chirurgie] 2014; 10(2): 179-182 DOI: 10.7438/1584-9341-10-2-15

Copyright: ( 2014 Vasiliu I, et al. This is an open-access article distributed unde the terms of the Creative Commons Attribution License, which permits unrestricted use, distribution, and reproduction in any medium, provided the original author and source are credited. 
at the age of 48 for episodes of paroxystic hypertension with spells. Anamnesis could not identify any other case in the family. The high levels of VMA ( $>50 \mathrm{mg} / 24 \mathrm{~h}$ at 3 determinations) confirmed the catecholamine excess, but the abdominal scanner was not diagnostic. The Iode Metaiodobenzylguanidine (I-mIBG) scintigraphy showed the presence of a $1.5 \mathrm{~cm}$ nodule in the left abdominal para aortic region (Figure 1). The patient refused surgery and had a satisfactory evolution with triple association of antihypertensive therapy.

After 11 years he was admitted in the Vascular Surgery Department for acute ischemia of the inferior limbs due to a voluminous para aortic tumor, which was resected. The pathology exam confirmed paraganglioma and described some atypical cells without being able to discriminate between benign or malignant pattern (Table I). At that time no endocrinological or cardiological control was performed.

After another one year he was admitted in the Endocrine Department for the re occurrence of the adrenergic syndrome (dyspnea, tremor, fatigue, weight loss, ventricular arrhythmia, hypertension with paroxystic episodes). The VMA was at $30.8 \mathrm{mg} / 24 \mathrm{~h}$.

The thoracic and abdominal CT-scan showed abdominal and thoracic metastatic tumors (Figures 2-4). The patient was referred to a specialized center were octreotide scintigraphy confirmed local recurrence and metastatic tumors in the lungs. He was proposed for therapy with Sunitinib with an initial good evolution. He died after 16 years from the initial diagnostic of paraganglioma.

\section{Discussion}

Paragangliomas are extra-adrenal tumors of neural crest-derived paraganglia that exist throughout the body in the distribution of the sympathetic and parasympathetic nervous [1]. The immunohistochemical markers, chromogranin and synaptophysin

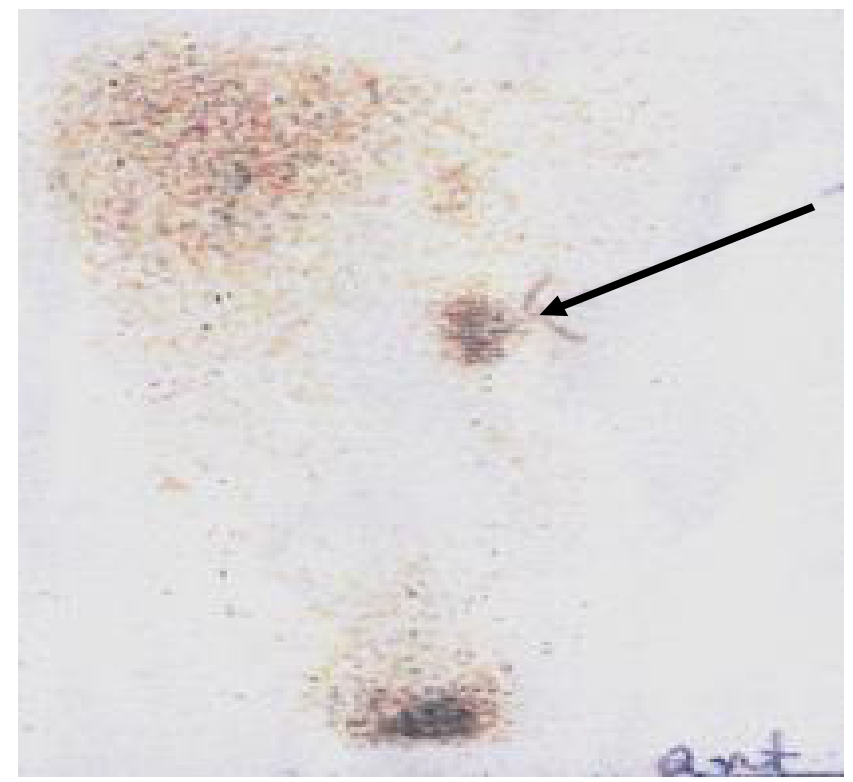

Figure 1: I $^{123}$-mIBG scintigraphy showing para aortic tumor.

Table I: Tumor immunohistochemical pattern.

\begin{tabular}{|l|l|}
\hline Parameter & Result \\
\hline MNF116 & Negative \\
\hline Chromogranin & Low positivity \\
\hline Synaptophysin & Low positivity \\
\hline Neuron specific enolase & Low positivity \\
\hline S100 protein & Positivity in sustentacular cells \\
\hline Ki67 & Rarely positive \\
\hline
\end{tabular}

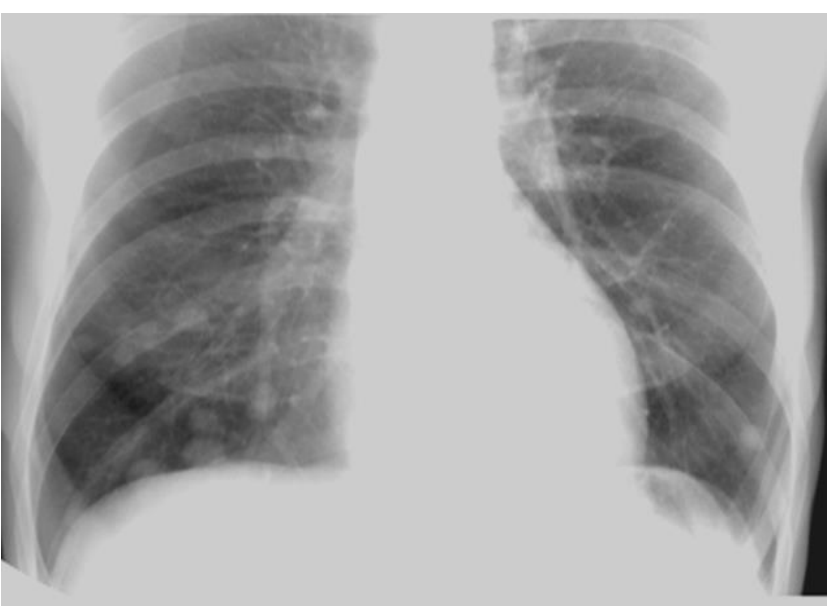

Figure 2: Chest X-ray: disseminated pulmonary nodules.

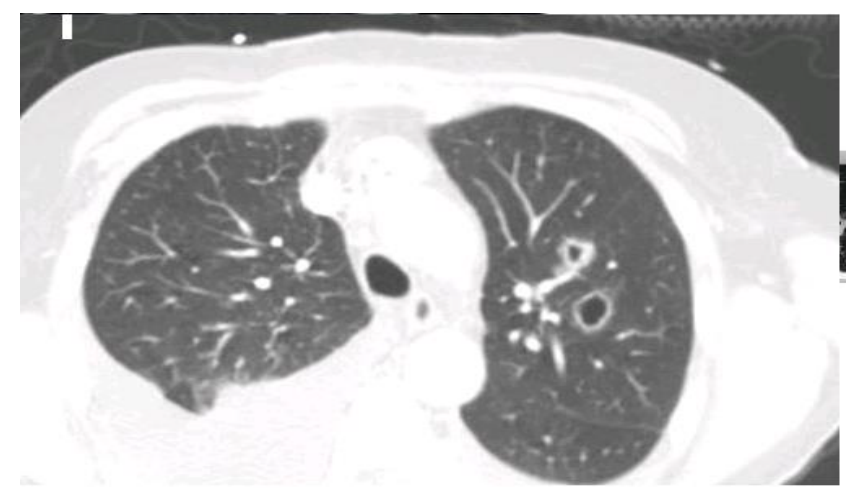

Figure 3: Thoracic CT-scan: disseminated pulmonary nodules.

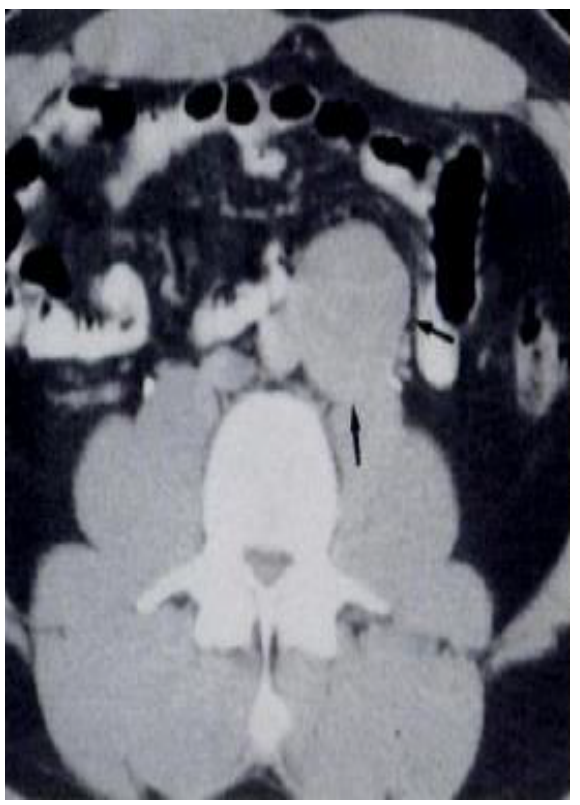

Figure 4: Abdominal CT-scan: abdominal recurrence.

immunoreactivity proved to be diagnostically useful, allowing, together with the absence of immunoreactivity for inhibin and melan $\mathrm{A}$, an unequivocal diagnosis of cathecolamine secreting tumors without discrimination between benign or malignant. To note, the mean count of sustentacular S-100 positive cells is lower in malignant than in benign pheocromocytomas [12]. 
Since there are no discriminatory markers for benign or malignant paraganglioma, the diagnosis of malignancy is established by demonstrating local tumor invasion or the presence of metastatic tumor at sites not known to contain chromaffin tissue. It is equally difficult to differentiate between malignant and benign tumors based on histological data since metastasis may be produced by histologically mature neoplasms [13]. In the presented case histological aspects and immunohistochemistry failed to establish the benign or malign pattern of the tumor.

Malignant paragangliomas have been well described in carriers of mutations of the succinate dehydrogenase B (SDHB) gene, but have rarely been associated with mutations in the succinate dehydrogenase $\mathrm{D}$ (SDHD) gene [14]. The mutations in SDHB may be associated with metastatic, clinically indolent, abdominal paraganglioma in some families [15]. The long evolution of the disease suggests that SDHB was the probable mutation in our case, but we did not have the possibility of genetic tests. He had 11 years of survival without any specific treatment (surgical or chemotherapy). After this period the adrenergic syndrome reappeared and the thoracic and abdominal CT-scan showed abdominal and metastatic tumors. He started therapy with Sunitinib with a good initial response and he died 4 years later.

Metastatic pheochromocytomas and paragangliomas are associated with increased angiogenesis. Sunitinib is an oral multitargeted receptor tyrosine-kinase inhibitor with antiangiogenic and antitumor activity, which targets platelet-derived growth factor receptor (PDGFR), vascular endothelial growth factors (VEGFR) 1 and 2, KIT, FLT3, and RET. This agent might be one therapeutic strategy for malignant pheochromocytomas and paragangliomas $[11,16]$.

Formerly, survival rate in malignant paraganglioma with distant metastases was considered quite low (12-34\% at 5 years). According to the recent literature, 5 years survival rate for patients with malignant catecholamine-secreting paragangliomas is significantly higher, $74 \%$. However, all these data are for patients who have been operated [17]. A recent study on 17 patients with progressive metastatic pheochromocytoma and paraganglioma showed an overall survival of 26.7 months with a progrerssion-free survival of 4.1 months [11].

Improvements in disease recognition and diagnosis over the past decades allow earlier diagnostic and treatment, and better survival. Nevertheless, many tumors remain unrecognized until they cause severe complications [18]. Nowadays in pheochromocytoma and paraganglioma 18F-FDG PET/CT is a superior tool in the localization of recurrent tumors [19].

Standard therapies (advanced surgery, radiometabolic therapy, chemotherapy and radiotherapy) have revealed suboptimal results in tumor size reduction and survival rate. Currently, there is no standard therapeutic protocol and thus some patients end up with overtreatment while others are undertreated. An effective molecular target therapy aiming at permanent control of these highly complex neoplasms should be the aim of future efforts [20].

Patients with progressive metastatic tumors and overwhelming symptoms are currently treated with systemic chemotherapy and radiopharmaceutical agents such as metaiodobenzylguanidine [21]. These therapies lead to partial radiographic response, disease stabilization, and symptomatic improvement in approximately $40 \%$ patients, and are associated with a modest improvement in overall survival duration [22]. Over the past decade, substantial progress has been made in clinical, biochemical, and radiographic diagnosis of pheochromocytomas and sympathetic paragangliomas. Approximately $50 \%$ of patients with malignant pheochromocytomas and sympathetic paragangliomas have been found to carry hereditary germline mutations in the succinate dehydrogenase subunit B gene (SDHB), and anti-angiogenic agents such as sunitinib have been found to potentially play a role in the treatment of malignant disease, especially in patients with SDHB mutations. In some patients, treatment with sunitinib has been associated with partial radiographic response, disease stabilization, decreased fluorodeoxyglucose uptake on positron emission tomography, and improved blood pressure control. These findings have led to the development of prospective clinical trials of new targeted therapies for metastatic disease [23].

A significant reduction in tumor volume of the malignant paraganglioma was observed when using sorafenib, a novel multityrosine kinase inhibitor that targets angiogenesis, the Raf-kinase pathway, the platelet-derived growth factor Ret, and c-Kit [24]. Recent molecular characterization of pheochromocytoma suggests new treatment options with targeted therapies, such as $90 \mathrm{kDa}$ heat shock protein (Hsp90) can be a potential therapeutic treatement for advanced pheochromocytoma [25].

\section{Conclusion}

The diagnosis of malignant pheochromocytoma and paraganglioma is challenging, since there is no a specific marker (molecular or histological) and the diagnosis remains a retrospective one, based on the presence of metastasis. Due to the rarity of the disease, the survival rate in these patients remains difficult to appreciate. Advances in molecular genetics helped in a more accurate evaluation of the malignant potential and in finding targeted therapy addressed to molecular mechanisms responsible of the initiation and progression of the malignant process. Thyrosine kinase inhibitors like sunitinib may induce a significant amelioration of survival rate, inducing disease stabilization in some patients. Prospective multi-center studies are needed in order to evaluate the efficacy of targeted molecular therapy in these rare diseases.

\section{Acknowledgement}

Drs I. Vasiliu and B. Hancearuc are Ph.D. students at "Gr.T. Popa "University of Medicine and Pharmacy, laşi. This paper is the result of the documentation undertaken during the doctoral internship.

\section{Conflict of Interests}

Authors have no conflict of interests to disclose.

\section{References}

1. Melmed S, Polansky KS, Larsen RP, Kronenberg HM (2011) Williams Textbook of Endocrinology. 11th edition Philadelphia: W.B. Saunders Com: 548-560.

2. Vulpoi C (2007) Urgente in endocrinologie lasi: Editura "Gr.T. Popa”- UMF lasi: 59-72.

3. Stenström G, Svärdsudd K (1986) Pheochromocytoma in Sweden 1958-1981. An analysis of the National Cancer Registry Data. Acta Med Scand 220: 225-232.

4. Sinclair AM, Isles CG, Brown I, Cameron H, Murray GD, et al. (1987) Secondary hypertension in a blood pressure clinic. Arch Intern Med 147: 1289-1293.

5. Anderson GH Jr, Blakeman N, Streeten DH (1994) The effect of age on prevalence of secondary forms of hypertension in 4429 consecutively referred patients. J Hypertens 12: 609-615.

6. Omura M, Saito J, Yamaguchi K (2000) Prospective study on the prevalence of secondary hypertension among hypertensive patients visiting a general outpatient clinic in Japan. Hypertens Res 27: 193-202.

7. Ungureanu G, Vulpoi C (2000) Hipertensiunea arteriala. In G Ungureanu Terapeutica medicala. Ed II-a. Iasi: Editura Polirom: 177-201.

8. Vulpoi C, Mogo̊̊̈̈ V, Ciobanu DG, Preda C, Ungureanu MC, et al. (2007) [Thyroid ultrasonography. Interobserver and intraobserver variations]. Rev Med Chir Soc Med Nat lasi 111: 864-871.

9. Mackenzie IS, Brown MJ (2011) Pheochromocytomas, paragangliomas, and neuroblastoma. In: Wass AHJ, Stewart MP, Amiel AS, Davies CM (Eds). Oxford Textbook of Endocrinology and Diabetes. (2ed) Oxford: Oxford University Press 798-799.

10. Lowery AJ, Walsh S, McDermott EW, Prichard RS (2013) Molecular and therapeutic advances in the diagnosis and management of malignant pheochromocytomas and paragangliomas. Oncologist 18: 391-407. 
11. Ayala-Ramirez M, Chougnet CN, Habra MA, Palmer JL, Leboulleux S, et al. (2012) Treatment with sunitinib for patients with progressive metastatic pheochromocytomas and sympathetic paragangliomas. J Clin Endocrino Metab 97: 4040-4050.

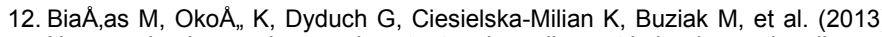
Neuroendocrine markers and sustentacular cell count in benign and malignant pheochromocytomas - a comparative study. Pol J Pathol 64: 129-135.

13. Simonenko VB, Makanin MA, Dulin PA, Vasilchenko MI, Lesovik VS (2012) [About the signs of malignant pheochromocytoma]. Klin Med (Mosk) 90: 64-68.

14. Havekes B, Corssmit EP, Jansen JC, van der Mey AG, Vriends AH, et al. (2007) Malignant paragangliomas associated with mutations in the succinate dehydrogenase D gene. J Clin Endocrinol Metab 92: 1245-1248.

15. Young AL, Baysal BE, Arjun Deb, Young WF Jr. (2002) Familial malignant catecholamine-secreting paraganglioma with prolonged survival associated with mutation in the succinate dehydrogenase B gene. J Clin Endocrinol Metab 87: 4101-4105.

16. Park KS, Lee JL, Ahn H, Koh JM, Park I, et al. (2009) Sunitinib, a novel therapy for anthracycline- and cisplatin-refractory malignant pheochromocytoma. Jpn J Clin Oncol 39: 327-331.

17. Lehnert H, Mundschenk J, Hahn K (2004) Malignant pheochromocytoma. Front Horm Res 31: 155-162.

18. Prejbisz A, Lenders JW, Eisenhofer G, Januszewicz A (2013) Mortality associated with phaeochromocytoma. Horm Metab Res 45: 154-158.
19. Fikri AS, Kroiss A, Ahmad A, Zanariah H, Lau W, et al. (2013) Localization and prediction of malignant potential in recurrent pheochromocytoma/ paraganglioma (PCC/PGL) using 18F-FDG PET/CT. Acta Radiol 55: 631-640.

20. Buzzoni R, Pusceddu S, Damato A, Meroni E, Aktolun C, et al. (2013) Malignant pheochromocytoma and paraganglioma: future considerations for therapy. Q J Nucl Med Mol Imaging 57: 153-160.

21. van Hulsteijn LT, Niemeijer ND, Dekkers OM, Corssmit EP (2014) (131)I-MIBG therapy for malignant paraganglioma and phaeochromocytoma: systematic review and meta-analysis. Clin Endocrinol (Oxf) 80: 487-501.

22. Tanabe A, Naruse M, Nomura K, Tsuiki M, Tsumagari A, et al. (2013) Combination chemotherapy with cyclophosphamide, vincristine, and dacarbazine in patients with malignant pheochromocytoma and paraganglioma. Horm Cancer 4: 103-110.

23. Jimenez C, Rohren E, Habra MA, Rich T, Jimenez P, et al. (2013) Current and future treatments for malignant pheochromocytoma and sympathetic paraganglioma. Curr Oncol Rep 15: 356-371.

24. Lin Y, Li Q, Huang W, Jia X, Jiang H, et al. (2013) Successful treatment of paraganglioma with sorafenib: a case report and brief review of the literature. Onco Targets Ther 6: 1559-1562.

25. Giubellino A, Sourbier C, Lee MJ, Scroggins B, Bullova P, et al. (2013) Targeting heat shock protein 90 for the treatment of malignant pheochromocytoma. PLoS One 8: e56083. 